Jurnal ELTIKOM, Vol. 1 No.2, Desember 2017, Hal 94-101 ISSN 2598-3245 (Print), ISSN 2598-3288 (Online)

Tersedia Online di http://eltikom.poliban.ac.id

\title{
ANALISIS TINGKAT ERROR SISTEM PENGATURAN SALINITAS AIR PEMBENIHAN BUDIDAYA UDANG GALAH
}

\author{
Syaiful Rachman ${ }^{1)}$, Yoenie Indrasary ${ }^{2)}$, Sunu Hasta Wibowo ${ }^{3)}$, Zaiyan Ahyadi ${ }^{4}$, Edy \\ Yohanes ${ }^{5}$ \\ 1,2,3,4,5)Politeknik Negeri Banjarmasin \\ e-mail: saifulrachman1@poliban.ac.id ${ }^{1)}$, Indrasary@ gmail.com²), sunu@poliban.ac.id ${ }^{3)}$, \\ zahyadi@gmail.com ${ }^{4}$, direktur@poliban.ac.id ${ }^{5)}$
}

\begin{abstract}
By applying regulatory system technology using a controller a built-in recovery medium can control equipment such as a solenoid valve, a water pump. Then the system was equipped with conductivity sensor that serves to monitor the value of parameters of water salinity and water flow sensor to determine the water volume, in this research to make a prototype of water hatchery regulation system 5 ppt while for the maintenance of prawn larvae 12 ppt, then analyzed against the system water volume error rate. Based on the result of the research, it was found that the error rate of the system that had been de-signed the tool testing shows the average error of salinity water volume in the experimental system on 5 pt media for fresh water volume indicated the system had an average error of 0.26 liters, while the salt water volume of 5ppt that the system had an average error of 0.18 liters. Then the system error rate on 12 ppt media experimental result for fresh water volume indicated that the system had an average error of 0.18 liters, while salinity water volume indicated that the system had an average error of 0.14 liters. For further research it will be necessary to add a PID or Fuzzy control system to the error rate that will occur could be reduced.
\end{abstract}

Keywords: Analysis, system error rate, water volume, water salinity.

\begin{abstract}
ABSTRAK
Dengan menerapkan teknologi sistem pengaturan menggunakan kontroler akan dibangun sebuah media pembenihan yang dapat mengendalikan peralatan seperti solenoidvalve, pompa air. Kemudian sistem ini dilengkapi sensor konduktivitas yang berfungsi untuk memantau nilai parameter salinitas airdan sensor water flow untuk menentukan volume air, dalam penelitian iniuntuk membuat sebuah prototypesistem pengaturan salinitas air penetasan sebesar 5 ppt sedangkan untuk pemeliharaan larva udang galah sebsar 12 ppt, kemudian dianalisis terhadap tingkat error sistem volume air pada penetasan dan pemeliharaan. Berdasarkan hasil penelitian diperoleh tingkat error sistem yang telah dirancang pengujian alat menunjukkan error rerata volume air salinitas pada sistem hasil percobaan pada media 5 ppt untuk volume air tawar menunjukkan sistem memiliki error rata-rata sebesar 0,26 liter, sedangkan volume air laut salinitas 5ppt menunjukkan bahwa sistem memiliki error rata-rata sebesar 0,18 liter. Kemudian Tingkat error sistem pada media 12 ppt hasil percobaan untuk untuk volume air tawar menunjukkan bahwa sistem memiliki error rata-rata sebesar 0,18 liter, sedangkan volume air laut salinitas menunjukkan bahwa sistem memiliki error rata-rata sebesar 0,14 liter. Untuk penelitian berikutnya perlu menambahkan sistem kontrol PID atau Fuzzy pada alat tersebut sehingga tingkat error yang akan terjadi bisa dikurangi.
\end{abstract}

Kata Kunci: Analisis, tingkat error sistem,volume air,salinitas air

\section{PENDAHULUAN}

$\mathrm{U}$ dang galah (Macrobrachium rosenbergii de Man) merupakan salah satu komoditas perikanan yang bernilai ekonomis tinggi baik untuk konsumsi dalam negeri dan komoditi ekspor. Permintaan pasar sampai saat ini cenderung meningkat, sedangkan penangkapan udang galah di alam semakin sulit), sehingga perlu dikembangkan usaha budidayanya. Untuk memenuhi kebutuhan tersebut diperlukan benih dalam jumlah yang cukup dan kualitas yang baik kendala usaha utama pada usaha budidaya udang galah di Kalimantan Selatan adalah kurang tersedianya benih, karena benih masih sangat tergantung dari stok alam [10]. Usaha pembenihan yang terstruktur harus segera dirintis untuk pemenuhan kebutuhan benih dan untuk restocking dalam rangka pemulihan populasi di alam yang 
semakin hari akan menipis. Beberapa balai panti benih telah berusaha mengembangkan pembenihan udang galah, di panti balai benih masih menggunakan metode manual, untuk pecampurankadar salinitas air. Pada pembenihan udang galah, untuk mengukur parameter salinitas air menggunakan alat ukur refraktometer atau hydrometer, Kemudian setelah memperoleh hasil salinitas awal yang telah di ukur dengan alat tersebut, selanjutnya dengan menambahkan sejumlah air tawar sebanyak yang diperlukan dan kemudian mengukur lagi dengan alat tersebut, apakah sudah sesuai dengan nilai salinitas air yang ditentukan [11]. Dengan berkembangnya teknologi, merupakan sarana yang sangat penting dalam pengendalian atau pengaturan dalam sebuah sistem peralatan yang diperlukan sebagai media untuk memanfaatkan dalam pembenihan memudahkan dalam pekerjaan dari segi efisiensi waktu dan tenaga dalam pembenihan sehingga akan meningkatkan pendapatan bagi petani pembudidaya[11].pada pengaturan salinitas air secara lebih efisien, dengan menggunakan sensor salinitas air dan sensor waterflow sebagai penghitung jumlah volume air yang akan dialirkan ke tank penampung salinitas air yang telah ditentukan seperti pemeliharaan larva udang galah sebesar 5 ppt dan 12 ppt [5]. Berdasarkan hal tersebut penulis untuk membuat suatu sistem prototype pengaturan salinitas air pembenihan udang galah. Penelitian ini akan dikerjakan meliputi instalasi pipa air, solenoid valve, pompa air, sensor salinitas air, sensor waterflow dan tank air. Kemudian dilanjutkan perancangan dan pembuatan sistem kontrol untuk mengatur salinitas air. Kemudian akan menganalisis tingkat error sistem volume salinitas air untuk pembenihan udang galah.

\section{STUDI PUSTAKA}

Bagian ini membahas teori dasar dari penelitian, yang untuk dikemukakan dan membahas penelitianpenelitian lain yang relevan dengan penelitian yang dikemukakan pada penelitian ini.

\section{A. Pengaturan salinitas air}

Pada kegiatan pembenihan dibutuhkan air bersalinitas 5 ppt dan 12 ppt untuk pemeliharaan larva, dan untuk membuat air dengan salinitas tersebut digunakan perhitungan dengan persamaan[2]-[3]-[4].:

$$
S_{c} V_{c}=S_{t} V_{t}+S_{l} V_{l}
$$

Scadalah hasil salinitas air campuran $\left(\mathrm{m}^{3}\right)$, kemudian $\boldsymbol{V} \boldsymbol{c}$ merupakan hasil volume air air laut campuran $\left(\mathrm{m}^{3}\right)$, sedangkan $\boldsymbol{V t a d a l a h}$ volume air air tawar $\left(\mathrm{m}^{3}\right)$, sedangkan $\boldsymbol{S t}$ adalah nilai salinitas air tawar awal $\left(\mathrm{m}^{3}\right)$, Sladalah salinitas air laut $\left(\mathrm{m}^{3}\right)$ kemudian $V l$ adalah volume air air laut $\left(\mathrm{m}^{3}\right)$

\section{B. Sensor waterflow}

Sensor water flow terdiri dari katup plastik, rotor air, dan sebuah sensor hall-effect. Prinsip kerja sensor dengan memanfaatkan fenomena efek Hall yaitu didasarkan pada efek medan magnetik terhadap partikel bermuatan yang bergerak. Ketika ada arus listrik yang mengalir pada divais efek Hall yang ditempatkan dalam medan magnet yang arahnya tegak lurus arus listrik, pergerakan pembawa muatan akan berbelok ke salah satu sisi dan menghasilkan medan listrik. Bentuk sensor waterflow ditunjukkan pada Gambar 1 .

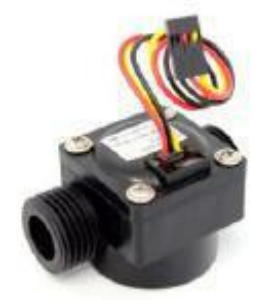

Gambar 1. Bentuk Sensor waterflow

Sensor terdiri dari tiga warna kabel yaitu merah, sumber tegangan sebesar 5-24 VDC, warna hitam adalah ground dan kuning adalah output sensor, sedangkan yang digunakan dalam penellitian ini menggunakansensor water flowparameter spesifikasiG1/2. 


\section{Sensor konduktivitas}

Sensor konduktivitas bekerja sebagai alat ukur daya hantar listrik (konduktivitas) suatu fluida. Dalam dunia industri alat ini beperan penting dalam kelancaran prosesmengukur, mengontrol, mendeteksi dan menganalisa suatu input dengan baik dan benar.Konduktivitas listrik adalah kemampuan suatu larutan untuk menghantarkan arus listrik. Arus listrik bergerak dengan efisien melalui air yang mempunyai kadar garam tinggi (konduktivitas elektrik tinggi), dan bergerak dengan resistansi lebih melalui air murni (konduktivitas rendah) [7]. Konduktivitas listrik juga mengindikasikan berapa banyak garam yang terlarut dalam suatu sampel. Bentuk sensor koduktivitas ditunjukkan pada Gambar 2.

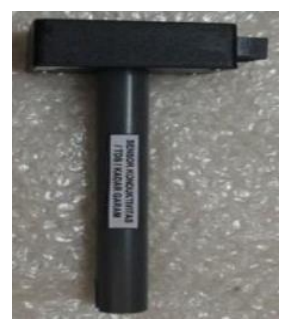

Gambar 2 BentukSensor koduktivitas

Dalam penelitian ini menggunakan sensor konduktivitas dengan karakteristik seperti ditunjukkan pada Tabel 1. Dengan tegangan kerja sebesar 5 Volt, tegangan operasional 3.0- 5 Volt, tegangan keluaran ADC dengan nilai $\leq 107-\geq 496$, respon waktu 0.1 sampai 0.3 Volt dan sensitivitas sebesar 0.1 sampai 0.5 Volt.

TABEL 1

KARAKTERISTIK SENSOR KONDUKTIVITAS

\begin{tabular}{ccccc}
\hline parameter & Symbol & Min & Max & unit \\
\hline Tegangan kerja & $\mathrm{Vcc}$ & - & 5 & Volt \\
Tegangan operasional & $\mathrm{Vcc}$ & $3.0-$ & 4.7 & Volt \\
& & & & \\
Tegangan keluaran & $\mathrm{ADC}$ & $\leq 107$ & -2496 & $\mathrm{ADC}$ \\
Respon waktu & $\mathrm{t}$ & 0.1 & 0.3 & Volt \\
Sensitivitas & $\mathrm{Vcc}$ & 0.1 & 0.5 & Volt \\
\hline
\end{tabular}

\section{Solenoid valve}

Solenoid valve adalah suatu alat kontrol yang berfungsi untuk membuka dan menutup valve/katup/kran secara otomatis menggunakan gaya magnet listrik pada penelitian ini menggunakan Solenoid valve dengan tegangan kerja 12 VDc. Cara kerja solenoid valve, bila kumparan/coil mendapatkan tegangan arus listrik yang sesuai dengantegangan kerja, sebesar 12 VDC. Sehingga akan tertarik karena gaya magnet yang dihasilkan dari kumparan selenoida tersebut.

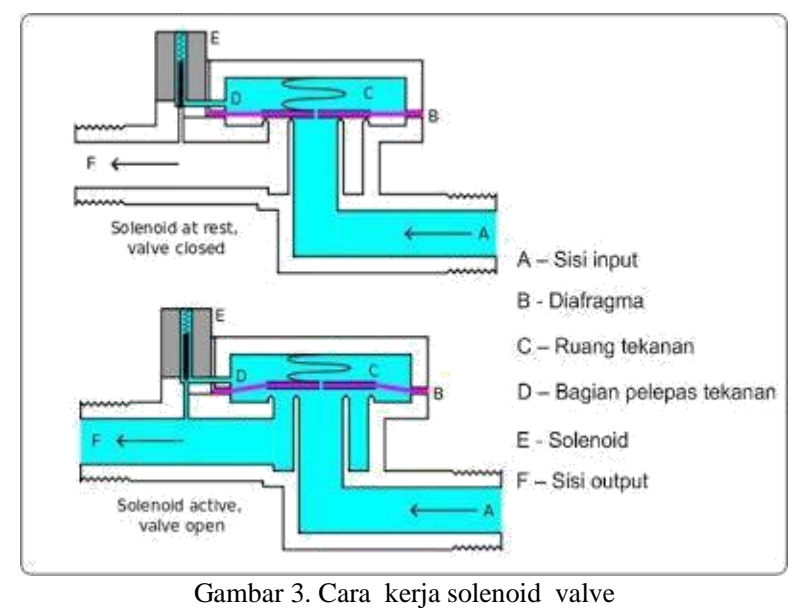


Dan saat keadaan tersebut. ditarik naik maka fluida akan mengalir dari ruang $\mathrm{C}$ menuju ke bagian $\mathrm{D}$ dengan cepat. Sehingga tekanan di ruang $C$ turun dan tekanan fluida yang masuk mengangkat diafragma. Sehingga katup utama terbuka dan fluida mengalir langsung dari A ke F, seperti ditunjukkan pada Gambar 3.

\section{METODE}

Metode pelaksanaan dalam penelitian ini meliputi tahapan yang dilakukan dalam perancangan blok instalasi system,desain system blok rangkaian, system control dan pengujian alat yang akan diuraikan sebagai berikut.

\section{A. Perancangan Instalasi Sistem}

Penelitian dilakukan dengan membuat perancangan sistem perangkat pipa (plumbing). Instalasi perangkat tersebut meliputi pemasangan (instalasi) tank air tawar (tank 1), air laut (tank 2), dan tank 3 untuk air yang telah telah diproses menjadi 5 ppt atau12 ppt untuk pembenihan, kemudian instalasi pipa(plumbing) meliputi pemasangan solenoid valve, motorpompa air dan sensor pendukung seperti sensor water flow dan sensor konduktivitas yang di pasang pada tank 2 dan tank 3, seperti ditunjukkan pada Gambar 4, Perencanaan Instalasi Sistem Pengaturan Salinitas Air.

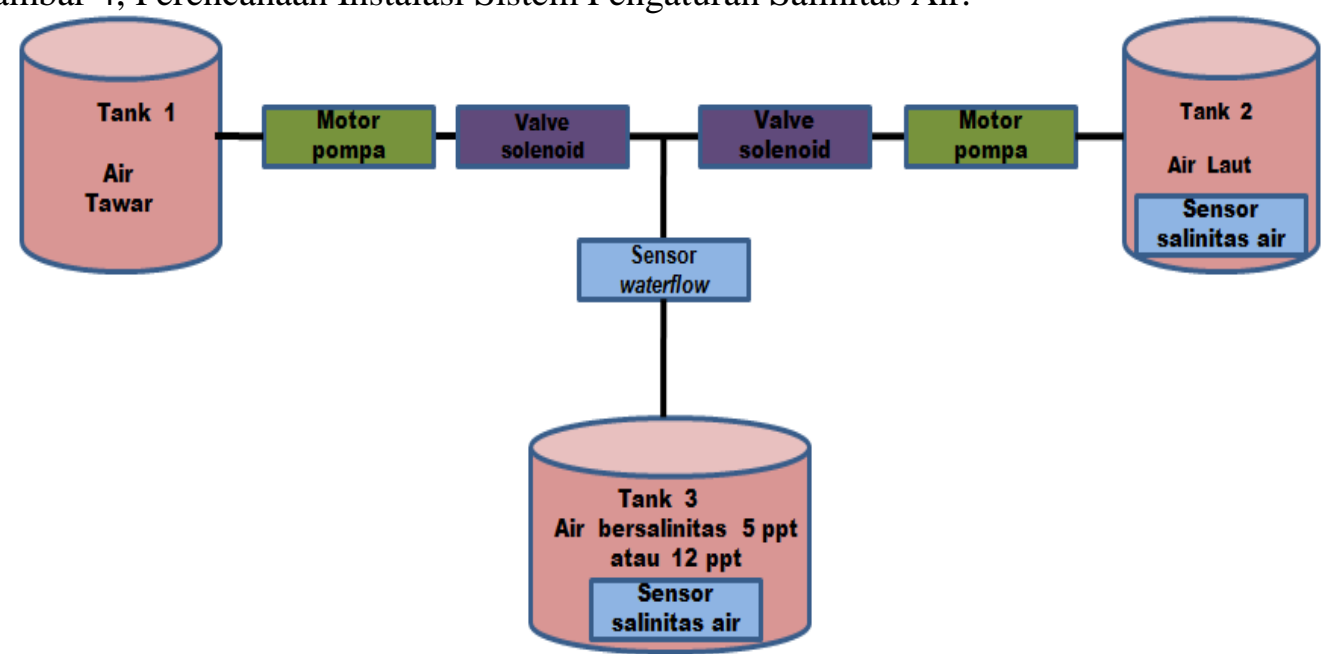

Gambar 4. Perencanaan Instalasi Sistem Pengaturan Salinitas Air.

\section{B. Desain Sistem Blok Rangkaian}

Setelah tahapan instalasi perangkat pipa, tank1 dan tank 2 , motor pompa air dan sensor telah selesai dilakukan instalasi, kemudian merencanakan blok rangkaian, meliputi perangkat hardware elektronika terdiri dari microkontroler meliputi output yang terdiri dari solenoid valve, LCD, input meliputi sensor water flow, sensor konduktivitas dan keypad (input tombol untuk menu pilihan).ditunjukkan pada Gambar 5.

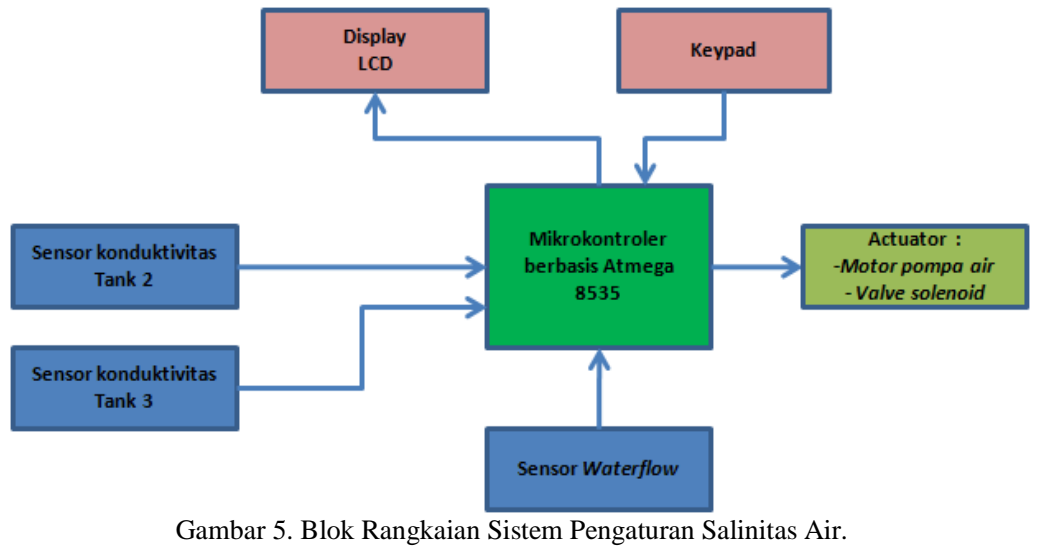


Cara kerja sistem yaitu keypad sebagai input yang akan menentukan jumlah salinitas air awal yang terbaca pada tampilan display (LCD), kemudian akan menghitung jumlah air baku yang akan ditentukan berdasarkan pilihan yaitu penetasan sebesar 5 ppt dan pemeliharaan larva udang galah sebesar $12 \mathrm{ppt}$.

\section{Perancangan Sistem Kontrol}

Diagram blok sistem kontrol umpan balik tertutup, yang akan digunakan pada penelitian ini, merupakan sistem yang menggunakan hubungan antara output (aktuator) dan input (sensor) yang diinginkan dengan cara membandingkannya. Hasil perbandingan ini merupakan deviasi yang digunakan sebagai alat kontrol dan membawa sistem pada keadaan yang diinginkan dengan menjalankan aktuator seperti solenoid valve, motor pompa air, berdasarkan parameter yang akan terbaca oleh sensorsehingga menghasilkan output yang sesuai dengan input yang diinginkanSeperti ditunjukkan pada Gambar 6.

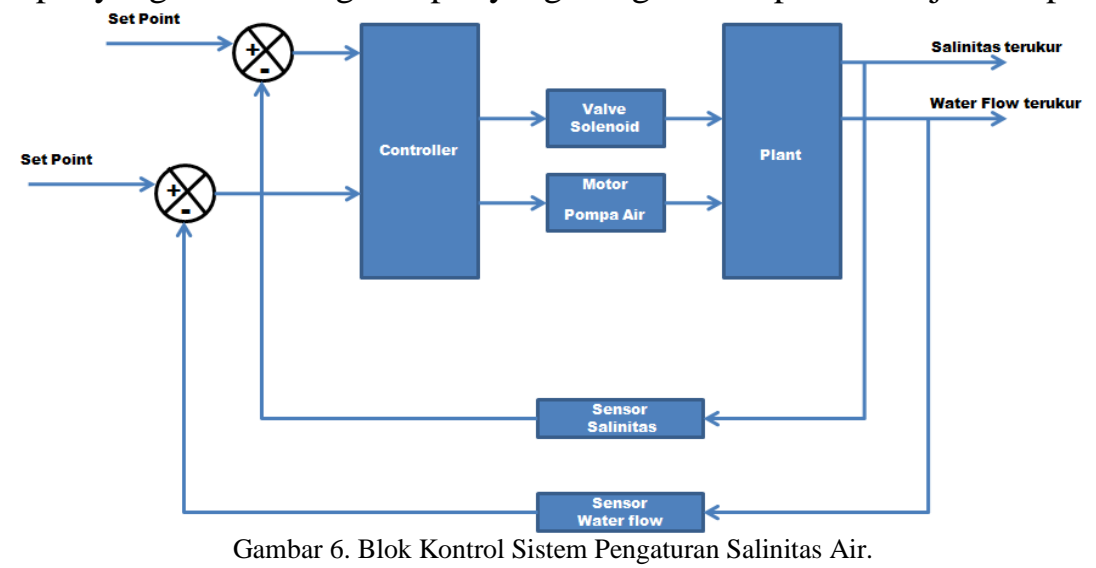

System kendali untuk mengendalikan beberapa perangkat dengan pengaturan jumlah air (per/liter) untuk membuat air bersalinitas pada untuk pembenihan udang galah, kemudian dengan menentukan set point dari tiap sensor untuk menentukan batas optimal pada media pembenihan dengan menggunakan pemograman Bascom AVR dengan modul minimum sistem.

\section{Pengujian Sistem}

Kemudian setelah pembuatan keseluruhan sistem telah selesai dilaksanakan. Selanjutnya ke tahapan pengujian dan analisis sistem. Kemudian dilakukan pengujian sistem alat dengan mengoperasikan sistem tersebut dengan di bantu dengan alat hydrometer. Untuk menguji kesesuaian hasil percobaan yang telah dilakukan dengan membuat tabel hasil percobaan dengan membandingan hasil alat ukur dan perhitungan. Selanjutnya menghitung rerata error dengan variabel (x). Hasil pengujian akan menunjukkan bahwa sistem memiliki error, nilai ini di peroleh dengan menjumlahkan semua nilai error dari setiap pengujian ( $\Sigma$ Error) dibagi jumlah pengujian keseluruhan, dan akan dibuat dalam bentuk table. digunakan perhitungan dengan persamaan[8]:

$$
x=\frac{\sum \text { Error }}{\text { jumlah pengujian }}
$$

\section{HASIL DAN PEMBAHASAN}

Dokumentasi prototype alat yang telah dikerjakan ditunjukkan pada Gambar 7, yang terdiri dari instalasi perangkat pipa, tank1 dan tank 2 merupakan tempat penampung air laut besalinitas $30 \mathrm{ppt}$ dan air tawar yang diambil dari bahan baku air PDAM Banjarmasin bersalinitas 0 ppt, motor pompa air terdiri dari pengerak untuk air tawar dan air laut yang akan dialirkan ke valve masing masing dari valve 1 dan valve 2 dan sensor konduktivitas sebagai pengukuran hasil dari pecampuran air laut dan air tawar yang akan dihasilkan, kemudian perangkat hardware elektronika terdiri dari microkontroler sebagai unit kontrol untuk pengendalisolenoid valve, LCD, sensor water flow, sensor konduktivitas dan keypaddan untuk sample membuat air dengan salinitas 5 ppt ppt dengan menggunakan volume air sebesar 30 liter dengan bahan baku air laut sebesar 30 ppt yang di ambil dari air laut lokal di kalimantan selatan yang diukur menggunakan alat tester salinitas merk hanna instrument, kemudian digunakan perhitungan 
menurut [2]-[3]-[4] yang dibuat dalam bentuk tabel, yang telah dijelaskan pada Persamaan(1) di bagian studi pustaka, dengan variabel yang telah diketahui, $\boldsymbol{S} \boldsymbol{c}$ adalah hasil salinitas air campuran (liter), selanjutnya $\boldsymbol{V} \boldsymbol{c}$ merupakan hasil volume air air laut campuran (liter), sedangkan $\boldsymbol{V t a d a l a h ~ v o l u m e ~ a i r ~}$ air tawar (liter), sedangkan $\boldsymbol{S t}$ adalah nilai salinitas air tawar awal (liter), $\boldsymbol{S} \boldsymbol{l}$ adalah salinitas air laut (liter) kemudian $\boldsymbol{V} \boldsymbol{l}$ adalah volume air air laut(liter).Sehingga diperoleh hasil, untuk perhitungan pada 5 ppt dan 12 ppt adalah sebagai berikut:

$$
S c=\frac{S l . V l}{V c}=\frac{30 p p t .5 \text { liter }}{30 \text { liter }}=5 p p t
$$

Maka diperoleh air tawar adalah sebesar 25 liter, Sedangkan untuk 12 ppt adalah sebagai berikut:

$$
S c=\frac{S l . V l}{V c}=\frac{30 p p t .12 \text { liter }}{30 \text { liter }}=12 p p t
$$

Maka diperoleh air tawar adalah sebesar 18 liter. Kemudian hasil perhitungan dibuat dalam bentuk Tabel dengan kelipatan per 10 liter dari maksimum 50 liter air yang digunakan seperti ditunjukkan pada Tabel 2 dan Tabel 3.

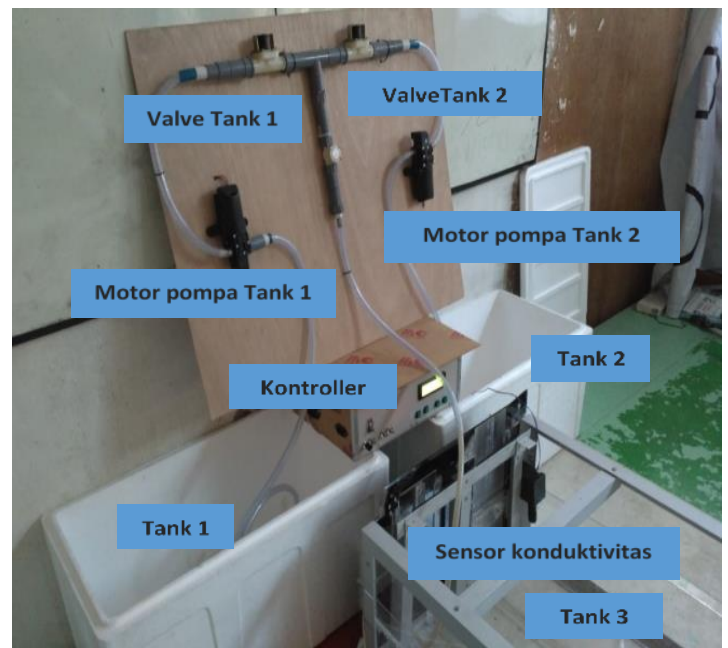

Gambar 7. Prototype Sistem Pengaturan Salinitas Air.

TABEL2

\begin{tabular}{|c|c|c|c|}
\hline \multirow{2}{*}{$\begin{array}{l}\text { Volume } \\
\text { Tank } 3\end{array}$} & \multicolumn{3}{|c|}{ Perhitungan } \\
\hline & Salinitas & $\begin{array}{l}\text { Volume Air tawar } \\
\text { (Liter) }\end{array}$ & $\begin{array}{l}\text { VolumeAir laut } \\
\text { (Liter) }\end{array}$ \\
\hline 10 Liter & $5 \mathrm{ppt}$ & 8.3 & 1.7 \\
\hline 20 Liter & $5 \mathrm{ppt}$ & 16.7 & 3.3 \\
\hline 30 Liter & $5 \mathrm{ppt}$ & 25 & 5 \\
\hline 40 Liter & $5 \mathrm{ppt}$ & 33.3 & 6.7 \\
\hline 50 Liter & $5 \mathrm{ppt}$ & 41.7 & 8.3 \\
\hline
\end{tabular}

HASIL PERHITUNGAN TANK AIR BERSALINITAS 5 PPT

\begin{tabular}{|c|c|c|c|}
\hline \multirow{2}{*}{$\begin{array}{l}\text { Volume } \\
\text { Tank } 3\end{array}$} & \multicolumn{3}{|c|}{ Perhitungan } \\
\hline & Salinitas & $\begin{array}{l}\text { Volume Air tawar } \\
\text { (Liter) }\end{array}$ & $\begin{array}{l}\text { Volume Air laut } \\
\text { (Liter) }\end{array}$ \\
\hline 10 Liter & $12 \mathrm{ppt}$ & 6 & 4 \\
\hline 20 Liter & $12 \mathrm{ppt}$ & 12 & 8 \\
\hline 30 Liter & $12 \mathrm{ppt}$ & 18 & 12 \\
\hline 40 Liter & $12 \mathrm{ppt}$ & 24 & 16 \\
\hline 50 Liter & $12 \mathrm{ppt}$ & 30 & 20 \\
\hline
\end{tabular}

TABEL3 
TABEL 4

\begin{tabular}{|c|c|c|c|}
\hline \multirow{2}{*}{$\begin{array}{l}\text { Volume } \\
\text { Tank } 3\end{array}$} & \multicolumn{3}{|c|}{ Pengukuran } \\
\hline & Salinitas & $\begin{array}{l}\text { Volume Air tawar } \\
\text { (Liter) }\end{array}$ & $\begin{array}{l}\text { Volume Air laut } \\
\text { (Liter) }\end{array}$ \\
\hline 10 Liter & $5 \mathrm{ppt}$ & 8.0 & 1.5 \\
\hline 20 Liter & $5 \mathrm{ppt}$ & 16.5 & 3.0 \\
\hline 30 Liter & $5 \mathrm{ppt}$ & 24.8 & 4.7 \\
\hline 40 Liter & $5 \mathrm{ppt}$ & 33.0 & 6.5 \\
\hline 50 Liter & $5 \mathrm{ppt}$ & 41.5 & 8.2 \\
\hline
\end{tabular}

TABEL5

\begin{tabular}{llll}
\multicolumn{4}{c}{ HASIL PENGUKURAN TANK AIR BERSALINITAS 12 PPT } \\
\hline $\begin{array}{l}\text { Volume } \\
\text { Tank 3 }\end{array}$ & $\begin{array}{l}\text { Pengukuran } \\
\text { Salinitas } \\
\text { (ppt) }\end{array}$ & $\begin{array}{c}\text { Volume Air tawar } \\
\text { (Liter) }\end{array}$ & $\begin{array}{l}\text { Volume Air laut } \\
\text { (Liter) }\end{array}$ \\
\hline 10 Liter & 11.9 & 5.8 & 3.8 \\
20 Liter & 11,9 & 12 & 7.9 \\
30 Liter & 11.9 & 17.8 & 11.9 \\
40 Liter & 11.9 & 23.7 & 15.9 \\
50 Liter & 11.9 & 29.8 & 19.9 \\
\hline
\end{tabular}

Kemudian hasil pengukuran tank air 3 bersalinitas 5 ppt dan 12 ppt dibuat dalam bentuk tabel seperti ditunjukkan pada Tabel 4 dan Tabel 5. Selanjutnya pada media 5 ppt, hasil dari Tabel 2 dan Tabel 4 diperoleh dari hasil pengukuran pada percobaan untuk volume air tawar menunjukkan bahwa sistem memiliki error rerata sebesar 0,26 liter. Nilai ini didapat dengan menjumlahkan semua nilai error dari setiap pengujian dibagi jumlah pengujian (5 kali). Menurut [8]. Secara perhitungan diuraikan adalah sebagai berikut:

$$
x=\frac{\sum 1.3}{5}=0.26 L
$$

Sedangkan diperoleh dari hasil percobaan untuk volume air laut salinitas $5 \mathrm{ppt}$ menunjukkan bahwa sistem memiliki error rata-rata sebesar 0,18 liter. Secara perhitungan diuraikan sebagai berikut:

$$
x=\frac{\sum 0.9}{5}=0.18 \mathrm{~L}
$$

Kemudian untuk $12 \mathrm{ppt}$, diperoleh hasil pengukuran dari Tabel 3 dan Tabel 5, perhitungan untuk volume air tawar menunjukkan bahwa sistem memiliki error rata-rata sebesar 0,18 liter, sedangkan perhitungan untuk volume air laut bersalinitas 12 ppt menunjukkan bahwa sistem memiliki error ratarata sebesar 0,14 liter.

\section{KESIMPULAN}

Dari hasil penelitian ini dapat ditarik kesimpulan antara lain, Hasil pengujian alat menunjukkan error rerata volume air salinitas pada sistem hasil percobaan untuk pada media 5 ppt untuk volume air tawar menunjukkan bahwa sistem memiliki error rata-rata sebesar 0,26 liter,sedangkan volume air laut salinitas 5ppt menunjukkan bahwa sistem memiliki error rata-rata sebesar 0,18 liter. Kemudian Tingkat error sistem pada media $12 \mathrm{ppt}$, hasil percobaan untuk untuk volume air tawar menunjukkan bahwa sistem memiliki error rata-rata sebesar 0,18 liter, sedangkan volume air laut salinitas menunjukkan bahwa sistem memiliki error rata-rata sebesar 0,14 liter. Untuk penelitian berikutnya perlu menambahkan sistem kontrol PID atau Fuzzy pada alat tersebut sehingga tingkat error yang akan terjadi bisa dikurangi.

\section{DAFTAR PUSTAKA}

[1] B.K. Chand ,et.al., "Effect of salinity on survival and growth of giant freshwaterprawn Macrobrachium rosenbergii (de Man),", Aquaculture Reports, Volume 2, Pages 26-33, India, 2015.

[2] H. Sutomo, et.al, "Inovasi Produk dan Perbanyakan Calon Udang Galah," Jurnal Budidaya Air Tawar Vol. 10,No. 2, hal 46-60, Nopember, 2013.

[3] Michael B. New Marlow,"Farming freshwater prawns, A manual for the culture ofthe giant river prawn (Macrobrachium rosenbergii),", Food and Agriculture Organization of the United Nations. ISBN 92-5-104811-8 .Rome., 2002 
[4] Madlen M. Habashy dan Montaser M. S. Hassan, 2011, Effects of temperature andsalinity on growth and reproduction of the freshwater prawn, Macrobrachium rosenbergii (Crustacea- Decapoda) in Egypt., IJESE .Vol. 1: 83-90, ISSN 2156-7549, http://www.pvamu.edu/texged Prairie View A\&M University, Texas, USA.

[5] Peter Mwangi, Elijah Mwangi,Patrick M. Karimi “A Low Cost Water Meter System based on the Global System for Mobile Communications," International Journal of Computer Applications (0975 - 8887) Volume 142 - No.12, May 2016

[6] Ratanak ou, , Breeding and rearing giant freshwater Prawn Larvae in Tanks UsingDifferent Salinity.,,IJERD.phnom penh.Cambodia. 2011

[7] Ria Sood, Manjit Kaur, Hemant Lenka "Design and Development of Automatic Water Flow Meter," International Journal of Computer Science, Engineering and Applications (IJCSEA) Vol.3, No.3, June 2013

[8] Sumardi, , Implementasi sensor level untuk alat ukur volume cairan serba guna dilingkungan industri, TRANSMISI, Jurnal Teknik Elektro, Volume 11, Nomor 2, Juni2009, hlm 91-99 Semarang, Jawa Tengah, Indonesia., 2009

[9] Yulius Kisworo, 2014, Jarak Genetik Udang Galah Dari Muara Sugai Barito, KintapDan Pagatan Sebagai Calon Induk Unggul. ZIRAA'AH, Volume 39 .No. 1, Hal 26-29, ,ISSN 1412-1468.

[10] Yus Warseno, S.Pi, , Optimalisasi Pemanfaatan Lahan Untuk PengembanganBudidaya Air Tawar Khususnya Pembenihan Dan Budidaya Udang Galah Skala Rumah Tangga, Teknologi Tepat Guna , Budidaya Perikanan, 2004 